\title{
化工业环境污染的防治分析
}

张仲勋 张露

陕西陕焦化工有限公司

DOI:10.32629/eep.v2i6.302

[摘 要] 科技的进步以及社会经济的发展,提升了人们生活质量, 同时在社会发展过程中也引发了诸多问题,环境污染即为其 中一种,其中化工业环境污染尤为严重,随着低碳环保概念的不断深入,对化工业环境污染进行防治日益受到人们重视, 基于此, 本文阐述了化工业环境污染的主要特征及其类型以及化工业环境保护的必要性,对化工业环境污染现状及其防止措施进行了 探讨分析。

[关键词] 化工业环境; 污染; 特征; 类型; 保护; 现状; 防治措施

化工业是社会体系的重要组成部分, 因其独特的生产模 式使得其会带来多种环境污染问题, 为了能够实现可持续发 展, 需要不断加强化工业生产模式的优化, 同时也需要对其 存在的环境污染现状进行防治。基于此, 以下就化工业环境 污染的防治进行了探讨分析。

\section{1 化工业环境污染的主要特征及其类型}

1. 1 化工业环境污染的主要特征

具体表现为: 一, 构成较为复杂, 如废水, 其是生产过程 中均会产生的, 在不同工艺的处理下, 最终废水的组成成分 也大不相同, 这使得处理工作变得较为困难。另外, 无论是废 水自身, 还是工艺处理过程, 均可能导致环境污染; 二, 其除 了组成成分复杂外, 也有形态各异的特点, 因此在废水之外 也会存在废物污染、气体污染, 不仅对环境有害, 更可能会危 及到人们的健康; 三, 其浓度过高, 简单的处理工艺已经无法 满足需求; 四, 其气味刺激性较强, 且排放量大, 一旦进入河 流即会污染整个水系。

\section{2化工业环境污染的主要类型}

依据化工业污染物的性质人们可将其分为有机污染与 无机污染, 依照污染物形态又可以分为废气污染、废水污染 和废渣污染。依照化工生产的流程, 化工污染物主要有以下 类型: 一是由于化学反应不完全导致的废料、二是化学反应 所伴随的副反应带来的生成废料、三是燃烧时的一些废气、 四是冷却废水、五是管道与设备泄露, 除此之外也包括其他 一些废弃物等。除了化学产品制造过程中会出现污染外, 在 化工产品使用的过程中也会出现一些污染情况, 主要是指对 化工产品过度滥用与不当使用等。目前, 我国在防治环境污 染方面也取得了一定成果, 基本控制了大的环境污染, 一些 地区与城市的环境也得到了改善。不过, 化工污染仍然广泛 存在于多个城市和地区。

\section{2 化工业环境保护的必要性}

化工业发展为社会发展带来了一定的经济效益, 同时也 给社会环境造成了不同程度的污染。人们只有意识到化工业 给环境造成的危害, 才能在实际工作中明确生产流程, 按照 相关废气排放标准, 降低企业对环境的污染。化工业在生产
过程中加大化工业环境保护在一定程度上也保证了企业员 工的身体健康, 保证化工业的正常生产。化工业工作人员的 身体健康得到了保障, 在生产过程中就能够安心稳定的工作, 实现化工业的正常管理。化工业环境保护可以改善化工业周 边的环境, 降低化学生产对周边群众的影响。化工业为周边群 众考虑, 采取有效的化工业环境保护措施, 将对化工业周边的 民众伤害降低到最小, 可以避免出现民众闹事的情况。化工业 环境保护对社会的长期发展具有很大的促进作用, 企业要想 获得长期发展, 就需要遵循科学发展观的理念, 在提升经济 效益的同时, 提高企业的管理水平。化工业环境保护是化工 业发展的保障, 也是实现企业利益最大化的途径。

\section{3 化工业环境污染现状的分析}

化工业作为工业化进程中的支柱产业之一, 对推动社会 经济发展具有重要作用, 但其带来的环境污染也非常严重。 据相关数据统计分析, 目前化学工业排放的废水、废气、废 渣分别占工业排放量的 $40 \% \sim 45 \% 、 7 \% \sim 10 \% 、 9 \% \sim 12 \%$, 在工 业部门位于前列。化工业在生产过程中对环境造成的污染有 以下几点: 第一、在生产过程中排放废水; 第二、在生产过 程中排放废气; 第三、长期化工生产对化工业周遭土壤的侵 蚀。化工业在生产过程中排放出来的废水没有经过科学有效 的处理, 一旦流入河流或者水库中, 轻则污染水源, 造成水生 物的死亡; 重则污染人们的饮用水源, 给人们的生命安全带 来隐患。化工业排放的废气是引发城市雾䨪的重要因素之一, 废气的扩散性很广, 化工业排放出来的废气会快速曼延到城 市的各个区域, 污染空气质量, 影响人们的身体健康。化工业 对环境造成的影响会巨大的, 形成雾霿的过程可能很简单, 但是消除雾䨪则需要投入大量的人力与财力。

\section{4 化工业环境污染的防治措施分析}

4. 1 积极推广应用清洁生产工艺

清洁生产工艺由两个部分组成, 一是清洁工艺, 二是清 洁产品。清洁工艺主要是指在提高经济效益的同时减少环境 污染; 清洁产品则是指对可回收性的产品进行二次加工。目 前我国针对此方面已经开展了研究项目, 但鉴于技术水平不 高导致其在实际应用时往往会存在些许不完善之处, 其对技 
术人员的要求也较高, 因此今后不仅要加强研究力度, 也要 针对人才进行技术培训等工作。

\section{2 不断创新科技创新}

创新是社会发展的主要推动力, 只有实现了创新才可以 更好的提升科技能力, 化工业应做好科技创新工作, 尤其是 “三废” 方面。在科技创新方面需要有足够的资金、技术和 人才咜备, 然而我国多数化工业并不能够完全具有相关资源, 因此国家层面还是要持续加强对此方面的关注和支持力度。

\section{3加强社会與论监督}

化工业发展不仅会促进经济发展, 同时也能够产生极大 的社会效益, 其中社会公众也就成为了被服务的一方, 但要 注意的是其也是环境保护的监督者。不难发现, 近年来社会 與论已经渐渐在诸多行业中起到了作用, 特别是约束作用, 其对于违规生产破坏环境的化工业所形成的社会舆论作用 往往可以促使其从自身做出改变, 遏制化工污染源头。对于 屡教不改的企业可以划入黑名单, 在此方面需要注意的是单 单依靠舆论是无法起到具体作用的, 还是要于管理制度、体 系结合应用。

\section{4 严格环境监督}

任何行业的发展均离不开政府部门的管理与支持, 化工 产业也是一样, 在此方面政府部门应充分发挥其职能, 将监 督管理工作做好, 而这也需要我国将相关法律法规进行完善, 只有这样才可以做到有法可依、有法必依。以目前情况来看, 我国相关环保部门虽然可以起到一定作用, 但其却只具有监 督权, 没有执法权, 往往只能够对相关企业进行警告和教育, 事实上化工业违法成本低也是造成环境污染的一大原因, 因 此今后应在此方面采取强化措施。

\section{5 提升环境保护意识}

若要从根本上杜绝或减少化工业环境污染, 首先应使化 工业具有环境保护意识, 在拥有该意识后才会采取相关措施 来对以往的问题进行解决。如, 可以在采购原材料时做好市 场调查, 在满足成本预算的情况下尽量优化原料质量, 减少 废气、废水的产生; 或是在此方面成立专门的部门, 由专人 负责生产监督工作, 对于在生产中投机取巧的员工进行指导 和处理, 避免因人为因素而带来更大的环境问题。总而言之 企业若要达到此目的, 则要对影响因素进行全面综合的考虑, 从而加强化工业环境污染的防治。

\section{5 结束语}

综上所述, 化工业环境污染的有效防治关系到社会环境 建设, 并且与化工业、生活发展等方面息息相关。近年来我 国为了解决化工生产带来的环境污染问题采取了诸多措施, 且收效明显, 但是由于各种因素的影响, 在实际防治中依然 存在诸多问题, 因此必须加强对化工业环境污染的防治进行 分析。

\section{[参考文献]}

[1]单琨.化工环境污染特点及防治策略探析[J].冶金丛 刊,2016,(4):67.

[2]侯智勇,周涛,陈天天.新形势下化工环境保护与安全 重要性[J].化工管理,2017,(34):123-124.

[3]郎志红.清洁生产技术在化工行业的应用[J]. 产业与 科技论坛,2016,15(17):60-61.

[4]胡星明.浅谈化工企业如何抓好环境保护工作 [J].江 西化工,2017,(5):141-143. 